\title{
Title: The Impact of the Physical Home Environment for Family Carers of People with Dementia: A Qualitative Study
}

Dia Soilemezi*

Department of Psychology, University of Portsmouth, UK

Phevos Kallitsis

School of Architecture, University of Portsmouth, UK

Amy Drahota

Science Faculty, University of Portsmouth, UK

John Crossland

School of Health Sciences \& Social Work, University of Portsmouth, UK

Rebecca Stores

School of Health Sciences \& Social Work, University of Portsmouth, UK

Alan Costall

Department of Psychology, University of Portsmouth, UK

*Corresponding author: Dia Soilemezi, Department of Psychology, King Henry Building, King Henry 1st Street, Portsmouth, PO1 2DY, UK.

Email: Dia.Soilemezi@port.ac.uk 


\section{Abstract}

Background: Most people with dementia are cared for by their families at home. This study investigated family carers' identification of barriers and facilitators when caring for a person with dementia at home.

Design and methods: Thirteen co-resident family carers were engaged in semistructured in-depth walking interviews. Interviews were recorded, transcribed and analysed using thematic analysis.

Results: Home environments can pose a number of challenges and opportunities. Aspects of the architectural and interior environment (e.g. size, condition, layout and accessibility, familiarity) are perceived as important (Theme 1) as well as a plethora of environmental strategies that encourage independence and comfort at home (Theme 2). Carers' scepticism, timing, costs, property characteristics and mistrust of services are some barriers to implementing environmental strategies (Theme 3).

Conclusions: Carers often improvise solutions through trial and error. Environmental strategies can create an enabling and comfortable home environment. 


\section{Introduction}

The prevalence of dementia is increasing and the numbers of informal carers is expected to rise (WHO, 2012). People with dementia are likely to experience difficulties when interacting with their social and physical environment as dementia progresses, making them sensitive to both over- or under-stimulation (Garcia, Kartolo, \& Méthot-Curtis, 2012). Given this dementia epidemic, evidence-based interventions and cost-effective approaches are needed to support these vulnerable people and their family carers, as a matter of public health priority (Gitlin, Marx, Stanley, \& Hodgson, 2015; WHO, 2012). Because the care of a person with dementia is typically more demanding and complex, family carers are more likely to provide intensive management in contrast to other carers (Torti, Gwyther, Reed, Friedman, \& Schulman, 2004; Zarit, Gaugler, \& Jarrott, 1999). On the other hand, carers who live with a person with dementia are especially likely to experience more depression and anxiety (Torti et al., 2004).

Non-pharmacological approaches, especially environmental interventions that create a safe, enabling, and predictable home environment, are considered key to improving the lived experiences of people with dementia and their carers (Garcia et al., 2012; Sadowsky \& Galvin, 2012; Soilemezi, Drahota, Crossland, \& Stores, 2017; WHO, 2012). Carers develop a range of useful individualised strategies to manipulate the environment, from microimprovisations, such as removing visual or auditory stimuli and de-cluttering their home, to major changes, such as changing the use of rooms (Wherton \& Monk, 2008; Wisniewski et al., 2003).

The person-environment fit model (the ecological theory of ageing) is the dominant framework in research on human behaviour and environmental aspects and the most frequently used model in environmental gerontology research (Kahana, Lovegreen, Kahana, \& Kahana, 2003; Lawton, 1990, 1997). This model argues that adaptation is needed to 
balance the demands of the external environment ("environmental press") and the individual's internal capabilities (“competence"). According to this model, environmental stressors, such as noise or limitations in physical space, can cause adverse outcomes to both the person with dementia and carers (Sadowsky \& Galvin, 2012; van Hoof \& Kort, 2009). In contrast, an optimal environmental setting could minimise maladaptive behaviours, namely wandering, agitation, and restlessness (Corcoran \& Gitlin, 1991).

Adequate environmental elements and strategies can not only provide comfort, functional support, social stimulation, and independence for people with dementia, but also support family carers to deal with the changing needs of their relatives (Brawley, 2001; Calkins \& Namazi, 1991; Corcoran \& Gitlin, 1991; Day, Carreon, \& Stump, 2000; Gitlin, Liebman, \& Winter, 2003). Increased functionality has been associated with aspects of the indoor environment, for example familiarity (Wherton \& Monk, 2008), layout of lived space (Marquardt, Johnston, Black, Morrison, Rosenblatt, Lykentsos, et al., 2011a; Olsen, Hutchings, \& Ehrenkrantz, 1999), lighting (Habell, 2010; Torrington \& Tregenza, 2007), thermal and acoustical environment (van Hoof, Kort, Hensen, Duijnstee, \& Rutten, 2010; Wong, Skitmore, Buys, \& Wang, 2014), and use of environmental cues (Garcia et al., 2012). Such compensatory strategies can be cost-effective, especially in reducing costs for informal care-giving as well as improving the sense of competence for carers (Graff et al., 2006, 2008). Nevertheless, some people may decide to relocate when their home is regarded as inappropriate or not meeting their current or future needs (Golant, 2015; Kaplan, Andersen, Lehning, \& Perry, 2015; Perry, Andersen, \& Kaplan, 2014).

When proposing dementia-friendly design and home interventions, one needs to address many elements. Firstly, both the needs of the person with dementia and the carer, because they are not always identical (Gitlin et al., 2013). Additionally, given their memory difficulties, people with dementia are likely to depend more on perceptual cues, mainly 
hearing, smell, vision and touch (Bentley, Alcock, Murrain, McGlynn, \& Smith, 1985;

Nygård \& Starkhammar, 2003). The senses, in communication with the environment, can support everyday activities; for example the sound of boiling water (hearing cue) is a reminder of making a drink, strategically leaving objects and preparing the environment ahead of a task (visual cues) are reminders of completing a task (Nygård \& Öhman, 2002).

Despite research indicating that carers regard environmental modifications or design as acceptable interventions (Robinson et al., 2007), researchers and policy makers have largely ignored the private home (Gitlin et al., 2013; van Hoof, Kort, van Waarde, \& Blom, 2010). To gather empirical evidence to support practitioners and policy makers, is therefore vital to explore family carers' own 'expertise' on the potential role of the home environment and useful environmental strategies. To our knowledge, there are few studies that explore carers' perceptions about the role of home design and modifications for dementia carers; these were based in the USA (Calkins \& Namazi, 1991; Olsen et al., 1999). The present study was conducted in the UK and aimed to explore carers' views on aspects of their home environment and available environmental strategies in order to clarify how the home environment can best support people with dementia and their carers at home.

\section{Design and Methods}

This paper is part of an exploratory qualitative study examining family carers' perspectives on different aspects of housing. A previous paper (Soilemezi, Drahota, Crossland, Stores, \& Costall, 2017) explored the subjective (meaning of home) aspects while the present paper focuses on the objective (architectural, interior physical and sensory) elements. Semi-structured phenomenological walking interviews were used to explore coresident carers' experiences of their living accommodation. 


\section{Sample}

A mix of purposive and convenience sampling was used, followed by snowballing and word-of-mouth referrals. Recruitment was carried out indirectly, using community gatekeepers who distributed study leaflets in local community groups, with an emphasis upon diversity, such as accommodation type, gender, age, and years of caring. The recruitment lasted approximately six months (January - June 2013). The sample was limited to Portsmouth (UK) and surrounding areas.

Carers of people with dementia $(N=13)$ were recruited, including two pilot interviews. All participants were interviewed once with no follow-up meeting. From all the potential participants who contacted the researcher, one was not interviewed due to physical illness. Current family carers, co-habiting with a person with dementia at the time of the study, with mental capacity to consent, were considered eligible. All interviews were digitally recorded and later transcribed verbatim; they lasted between 39 and 79 minutes (average 60 minutes).

\section{Procedure}

The Science Faculty Ethics Committee (University of Portsmouth) and Portsmouth City Council reviewed this study. A mutually suitable day and time was arranged to visit carers in their own homes. A few days before the interview, participants received a provisional interview schedule, which was advised by a support group leader, to minimise carers' anxiety and encourage reflexivity. Participants provided informed consent and were allocated a participant number. A shopping voucher worth $£ 10$ was given to each participant at the end of the interview as a 'thank you' and an acknowledgement of their time.

During the first part of the interview, carers were asked some demographic questions and then about their views on the impact of their home environment. In the second part, carers were interviewed while walking around their home. There was no predetermined route; 
the carers themselves were asked to lead the home tour. All rooms used by the carer were observed. Photographs, direct observations, and house plans were taken (with permission) to support the data analysis and contextualise carers' verbalisations of their lived experience.

The walking interviewing is an established method in geographical and urban planning research, but is a relatively new approach in dementia studies. In comparison with the standard sedentary interviews, they have the advantage of encouraging participants to connect with their surrounding environment and thus eliciting rich and environmentally sensitive data (Carpiano, 2009; Evans \& Jones, 2011). By directly observing the participants in their natural setting, walking interviews allow for closer examination of environmental practices and interactions (Carpiano, 2009).

\section{Interview schedule}

The aims of the present study and the development of the interview questions were structured by the ecological theory of ageing, previous research publications and systematic reviews. Examples of the questions used are: 'Thinking about this room and your every day tasks, how easy or difficult is it to care for your relative in here?", "What task / behaviour / equipment do you find particularly troublesome or useful in here and why?'. When barriers or challenges were mentioned by the carers, they were asked to think of suggestions for improvement. Elements of the environment (e.g. photographs, furnishing) and daily caring activities (e.g. toileting) were used as prompts, when appropriate, to understand how carers conceptualised their environment and tasks.

\section{Analytic approach}

Following the approach by Braun \& Clarke (2006), thematic analysis was carried out in six phases. The first author (DS), a registered PhD student at the time of the study with 
previous experience interviewing participants and supporting people with dementia, designed the study and conducted the data collection and analysis. Firstly, all the transcribed interviews and the researcher's notes were read repeatedly by the first author (DS) to allow familiarisation with data and initial ideas. Visual material (photographs, house drawings) and the researcher's journal were also used to assist with familiarisation of data. This was followed by line-by-line coding of all transcripts and notes. These initial descriptive codes were intended to capture the relevant data; the codes could be a couple of words, sentences or a whole paragraph. The next step was to identify similar codes and cluster them together to create initial themes. In order to ensure that these initial themes 'worked' independently and together, the initial codes and transcripts were checked to ensure the themes represented the relevant data and the entire dataset. Then every theme and subtheme was named and defined. Once the analysis was complete, the first author (DS) met with the research team to discuss the coding and validate the final themes. Once the findings were written, all authors agreed on the final refinement and selection of participants' quotations. An audit trail of all analytical stages was saved in QSR International's NVivo 10 Software. Although the analysis was data driven, previous research was used as a guidance to categorise the findings according to architectural and design principles (van Hoof \& Kort, 2009) and home modifications (Messecar, Archbold, Stewart, \& Kirschling, 2002; Pynoos, Steinman, Do Nguyen, \& Bressette, 2012). The second author (PK) prepared the floor plans and spatial analysis.

\section{Results}

\section{Participants}

All participants were family carers (12 spouses, 1 adult child), of British ethnicity, White, and lived in a variety of properties, with an average residency time of 18 years (range 
$<1$ to 45 years). Participants had provided care for their relative for an average of 3.5 years, ranging from 1 to 6 years. They lived in their own homes that varied in type, layout and size, ranging from a one-bedroom apartment to four-bedroom house (Table 1).

\section{Findings}

Three main themes, each with subthemes (Table 2), were identified: (1) important environmental aspects, (2) adapting and improvising, and (3) barriers to implementing environmental strategies.

1. Important environmental aspects. This theme explores the importance of the home as a setting of care provision and focuses on home features, in terms of both architectural and interior design. All the participants in this study reported that their home environment presented some barriers to a lesser or significant degree and they had employed minor or major adaptations, mostly to compensate for the physical weaknesses rather than cognitive deficits of their relative. Carers lived in a variety of accommodations, which affected how they reported dealing with individual challenges in promoting safety and wellbeing at home. In summary, carers reported certain elements that were regarded as very important for either promoting or hindering dementia care: (1) architectural elements regarding the scale of the building, such as size, layout and access, natural light and views, physical condition, and (2) interior design elements regarding the scale of the room, such as decoration and furnishing, brightness and colour, materials and finishes, and the internal sensory (acoustic- thermal- olfactory) environment.

1.1 Architectural elements. The majority of carers believed that dwelling size adds to safety. A large property was considered helpful as it can offer choices and space to accommodate equipment, modifications (or even conversions), and implement various 
environmental strategies. Ten carers agreed that having more space makes life easier, functional and practical, and enables safe care delivery and accessibility. Lack of enough space meant less room for storage, equipment and appliances and possibility for converting rooms. Lack of space was the reason that two carers decided to move with their relative to a more spacious property. One carer, who moved to a four-bedroom property explained:

\author{
We've got more space [here] to move around, as we need more gadgets to help \\ her, and there is more room... but there [the old flat] wasn't much room; I \\ couldn't get the wheelchair around. In the flat we couldn't have room to have \\ the hoist (CA02).
}

\begin{abstract}
Nine carers reported that a spacious property provided extra rooms, for example a separate bedroom for the carer (or other family members or paid carers) to sleep, space for ideally a second bathroom and availability for, as two of the participants put it, 'escape spaces'. The latter was thought as paramount to enable them to comfort themselves, relax and restore their identity.
\end{abstract}

It's good that there are rooms to go to, where we don't have to be together; if we were stuck together in a little flat, I think I'd go mental [laughs]... the small room I've turned into my office, which is one of my escape rooms [laughs]... if I was stuck together in a small room, I don't know... I couldn't just sit there (CA05). 
On the other hand, the two carers who had moved to a smaller property (one-bedroom apartments) regarded it as more handy and manageable, felt they were more in control, and that it required less attention and housework.

It's a help to me because it's small, and convenient... most of my time, really, is taken up looking after my husband, giving him lots of tablets, and preparing the meals. It's enough to do without having a big house to look after (CA01).

The layout and accessibility of the house were perceived as important in terms of safety and comfort. One-level accommodation, open living space, big windows, flooring and proximity of rooms were mentioned as helpful home elements. Four carers who lived on one level, with no stairs to tackle, explained that it was beneficial and less stressful in terms of accessibility, “I ain't gotta go up and down stairs. Everything's on this level and I know my wife's in a matter of three rooms" (CA08; Figure 1). Eight carers who lived in houses considered the stairs to be a risk for falls, incontinence accidents, and a reason for constant vigilance. Two carers considered the presence of stairs as a reason for future relocation to a property that will not need further modifications.

I feel now that the house is not fit for what we need... They [stairs] are very steep and they do worry me... I can never get out; I worry about him falling... I just feel that with no steps and everything, that it would make it, in a way I suppose, it might be easier for me because I won't have to be following him everywhere (CA07; Figure 2a,b). 
In contrast, one carer living in a three-storey house, actually perceived stairs as a positive element for two reasons:

Because it's such a long way to go, he wouldn't, I hope he wouldn't, go down three flights of stairs, and wander off because it's such a long way... in a way it's positive, because that's the only exercise my husband gets, is going up and down the stairs (CA10).

Another important aspect of the layout was open-plan living space. Eight carers thought it was easier and more practical to supervise their relatives as an open-plan layout offers visual and acoustic access, "it's got a flowing to it and you are not diving off to different places. And there is no hiding places if you know what I mean... being aware what is going on" (CA11). One carer altered the design to allow for direct observation by knocking down the wall between the kitchen and living room. However, four carers favoured closed rooms, especially the kitchen, where they often did not allow the person with dementia to enter. In general, participants considered a helpful layout to have a toilet on each level, an outside space and easy access for wheelchair users: "probably thinking about it, we've had less accidents since that [toilet]'s been there [downstairs] because it's not so far to go" (CA05).

Ten carers reported that the location and proximity of the rooms was also important. Ideally they would like an en-suite or the bedroom next to the bathroom, "he's going to the toilet 3-4 times in the night, so to have the bathroom right next to him is beneficial" (CA10). For those carers who sleep in separate bedrooms, the carers' bedroom would need to be next to the main bedroom for closer supervision and next to the stairs to alert them in the night. 
Another aspect of the architectural design was the presence of large windows to allow people to look out and bring more natural light in. A home with large windows was perceived as providing sensory enrichment and pleasing views to the outside world for the person with dementia, as well as comfort and escape for the carer, "even if it's raining or snowing, anything, I don't mind. I can see out and I'm not sort of enclosed too much" (CA12).

The condition of the property was regarded as problematic by two carers when it was old and requiring a lot of work and facilitative when there was no need for any improvements or alterations.

We've always had old houses and they're not so easy to heat and obviously not so easy to keep, keep clean and tidy because they're older... this is the first time we've had a, a newer house and it is much easier (CA13).

1.2 Interior design aspects. Maintaining familiarity in the domestic environment (decoration and furnishing), maintaining environmental order and avoiding unnecessary changes and re-arrangements were considered crucial in promoting the relative's well being and minimising confusion. Even for those carers who moved to a new home, maintaining familiarity was perceived as important to make the transition more smoothly. 


\begin{abstract}
I've put everything in the same place as it was in the flat... I've put things in the same cupboards and in the same areas so that if he, you know, like with making a cup of tea or coffee which he can still do, um where the cups are and where the coffee is and where the tea is and everything, where the, where the spoons are etc (CA13).
\end{abstract}

Ten carers considered brightness, in addition to the previously mentioned natural lighting from windows, important for (literally) lightening their mood: "Lots of light makes me feel better" (CA05). The same was reported by five carers about the use of colour as important to improve the home aesthetics and subsequently improve the carers' mood: "First colour I've introduced is to my bedroom... I think I'm trying to lighten my life a bit... this is the first time I've actually added colour" (CA06).

Carers also commented on qualities of their flooring and three favoured carpets as they were perceived to add comfort and warmth. Six carers, however, favoured the hard type of flooring, such as tiles, lino or wooden floor, as they perceived them as more practical and easier to clean, "sometimes there is an accident... it's a lot handier when you can wipe a floor" (CA04). One carer explained that in anticipation of regular stains, she kept the old carpet in the bedroom, "if something happens and you spill something, it doesn't matter, it's not a new carpet" (CA02). However, one carer removed the existing lino floor because her mother thought it was cold: "She wouldn't go in on the floor because it was white and she thought it as marble and cold" (CA02).

Five carers also explained that they were concerned about the thermal comfort and worried whether the temperature was appropriate and comfortable for their relative, and in some cases the heating was kept constantly on. Unpleasant smells from 
incontinence, were also identified as problematic for two carers. Good ventilation and fresh air were important but sometimes not possible or practical.

The domestic acoustic environment was another important element. For 11 carers creating a peaceful environment was important to ensure they can relax and get enough sleep.

Where we were before... it was always a very noisy environment. Here it's very quiet... I'm getting more sleep and I'm more relaxed so it has helped me a great deal, which then helps with the caring of course (CA13).

Nine carers also mentioned that listening to music, having the radio or music on was helpful for company and as a way to improve their mood, "I do like the music, I can't bear it so silent... I always, always have my music on" (CA04).

2. Adapting and improvising. This theme explores the environmental strategies that carers used to compensate for difficulties, make daily life more practical, help them feel in control and give them some 'peace of mind'. Overall, changing the environment was seen as a helpful strategy to optimise safety, comfort, and independence while protecting their dignity and boosting the confidence of the person with dementia. For the carers this in turn meant less time spent in supervising and better outcomes (e.g. less burden, more sleep). The bathroom was considered the most problematic room, and all the carers had made modifications, such as raised toilet, walk-in wet room, shower seat, door reversal, bath lift, grab rails (Figures 3-5). Other types of modifications were implemented in areas of high-risk concern such as the stairs (e.g. banister, stair lift; Figures $6 \& 7$ ) and, in a few cases, the kitchen. The bedroom and living room (and/or conservatory if available) were considered the 
most preferable rooms in the house. Carers installed adaptations and equipment in nearly all rooms, except in just one case the living room. Notably, all carers adapted their home space, objects and their behaviours proactively or reactively, following either the advice of professionals or by improvising their own solutions.

\subsection{Additive and transformative strategies: carers added novel solutions within their}

environment. Carers used a number of technologies and equipment to make life more safe and practical, by bridging the gap between functional status and environmental demands. These included: everyday technologies, assistive devices, and equipment. Everyday technologies refer to appliances and gadgets that are commonly used without addressing any care need (e.g. tv, kitchen appliances,); assistive devices compensate for mainly cognitive deficiencies and support care need (e.g. sensors, alarms; Figure 8), and equipment to mainly address physical/mobility difficulties and can be affixed (grab rails, stair lift) or non-affixed items (hoists or chair/bed raisers). Overall, carers reported finding everyday technologies very helpful; some wished they had more appliances, specifically a dishwasher and a tumble dryer: "We're lucky we've got washing machines [laughs]... I think the modern things that we've got now is helpful" (CA04). Seven of the carers used computers and laptops to access online services (e.g. shopping, banking), for entertainment and communication with family and outside world. As a result of spending long hours indoors, seven carers reported spending a lot of time watching television. To compensate for their own visual deterioration, carers added new lighting, "I’ve had it [a floor lamp] a year or so, but it's invaluable to me" (CA06), or simply adjusting the existing lighting, for example leaving the light on in the corridor or in the bedroom: "I have a little lamp plugged in... It's on all the night and she can see what she wants to do" (CA11). Two carers controlled the temperature by added more radiators in their relative's bedroom. 
I have the monitors on the bedside cabinet so I can hear her immediately and I can reach through here in seconds...I can actually be anywhere in the house, and that's the biggest improvement (CA02).

\begin{abstract}
Although assistive devices were used by carers, the equipment (e.g. bed guard, commode, hospital bed, raised toilet seat, stair gates, ramp, stair lift, shower seat, handrails) was put in place for the relatives' safety and independence. In seven cases, carers reported that they were making use of the equipment as well, for example, using the stair lift to get the laundry and shopping upstairs, "it saves me struggling" (CA13). All the carers recommended the use of equipment as a means to increased quality of life for both the carer and the person with dementia.
\end{abstract}


Very helpful; I just wouldn't be able to cope. Because I'd be forever sort of glued to my wife, all the time... it gives her more independence... which I think makes, helps her dignity as well... I used to have to just follow her up... it was more sort of a confidence booster for the wife than it was anything else. But the stair lift is ideal because... it gives her more independence (CA12).

Providing visual cues (Figure 9) and use of colour was another supplementary strategy and reminder to assist the person with dementia with initiation or completion of a task. It included leaving notes, using calendars, leaving the door ajar, putting up labels and messages on boards, "if he couldn't find me, he could go to the board and see what was happening that today" (CA05).

One carer used colour to highlight objects, to attract the attention of the person with dementia and assist with personal care.

Sometimes he'd go to the toilet and I didn't realise he wasn't always going into the toilet... they said that if you put a dye down the toilet, that guides them to the colour... that helps them to concentrate more (CA04).

Carers also commented on the importance of personal items and photographs as a strategy to enrich the environment and support familiarity. This was especially important for those couples who had moved to new residences and wanted to personalise the new home. Family objects and pictures were considered important for the person with dementia to provide sensory enrichment and reminisce, but also for the carers, “makes me feel like I'm still part of a family even if I don't see them very much" (CA05). 
Five carers used blocking and locking (doors, cupboards, and cabinets) as a strategy to control behaviours, access to rooms or objects. In order to control access to areas or objects, four carers added new locks on doors and cupboards. One carer solved the unpleasant smells in her internal environment by ensuring that doors are closed, “sometimes it doesn't smell very nice and it would permeate right through so I had a, a spring put on there so it would close the door" (CA13).

Although professionals recommended some of these strategies, some of the carers had themselves improvised these in response to an unanticipated crises, for example a temporary deterioration due to an infection: "He was sort of banging around on the walls; and I had to block the stairs off at night, I had to put something across so that he couldn't get downstairs" (CA03).

Carers also rearranged their space and objects ranging from a smaller scale to transforming a whole room in trying to monitor and prevent confusion and risks. Examples of smaller rearrangements done by seven of the carers and were: covering mirrors to prevent confusing the person with dementia (Figure 10), shortening cords, repositioning the bed, reversing doors and relocating hazardous items to top shelves: "I've reversed a couple of doors, because the downstairs toilet door used to open inwards, whereas if you collapsed behind there, we'd never get the door open" (CA12).

The most common room transformation was the installation of a walk-in shower with nonslip flooring, which was done in five of the properties; even four carers that had not installed one, considered it safer than the bath, useful for future deterioration and handy for other family members (e.g. grandchildren): "The shower's made an awful lot easier... that's more practical... it's brilliant... you got the whole length of it, so it's a lot safer. He's not gonna fall so much" (CA03). 
2.2 Subtractive strategies: the removal of elements. Nine carers considered decluttering and simplifying the environment to be helpful in making their house more practical and safe. Potential fall hazards were rugs, slippers, walkers with brakes, and small pieces of furniture, which carers had to remove in order to prevent any accidents and to ensure a clear and safe walkway for the person with dementia. Apart from removing or hiding hazardous items, two carers also hid objects to add more comfort: "I have to hide the commodes because it's not very nice when people come in" (CA10).

Removing physical barriers was considered as a strategy to add more safety around the house, meaning that sometimes carers had to balance or compromise between safety, privacy or comfort in their own home: "I was very close to taking the bathroom door off, cause she fell inside with the door shut and the compromise was... if I take the door off, I lose privacy as well” (CA02).

\subsection{Behavioural and structuring strategies: manipulating behaviour, existing}

elements or objects. Maintaining a structured routine and familiarity was considered an effective strategy to a predictable and simplified way of life and care. Two carers, who had professional assistance, made sure that the paid carers were familiar with the caring routine too, "you've got to have a routine... So the girls [the paid carers] know the routine" (CA06).

Organising and simplifying was also used by carers to prepare or re-arrange the space for a task for convenience and reduction of time and demand, "I prepare his room for him: pull back the bed, put his pyjamas where he can see them, put the toothpaste on his brush" (CA06). Some carers rearranged cupboards, cabinets and drawers; some carers invented their own organising systems: "I've sort of laid all his clothes out in certain places and make sure they're always in those places so that he knows where they are ... all to hand so it makes life a lot easier, yeah" (CA13). 
Additionally, some carers controlled the internal (thermal, olfactory and acoustic) environment at home by pulling the curtains to stop the draft, keeping the heating constantly on, and creating a positive acoustic environment by minimising internal or external noise: "I wouldn't have the radio in this room... I might have a little bit of music but I wouldn't have a radio up" (CA02).

3. Barriers to implementing environmental strategies. This theme represents the five main factors identified by the carers as preventing them from adapting their domestic setting and it involves characteristics of the carer, the involvement of professional practitioners, property characteristics, available funding and timing.

\subsection{Carers' scepticism over the use and importance of environmental strategies.}

Scepticism was the main reason carers did not implement environmental solutions. Four carers claimed that the environment had no influence on the behaviour of their relative, and did not consider it worth exploring further: "It's his health; the flat doesn't make it worse... There is no problem in the environment" (CA01). Six carers expressed some scepticism about the usefulness of the equipment and assistive technologies. Four carers believed that their relative would not be able to operate any new device or use any environmental strategy due to functional deterioration, “I don't think it would make any difference if it [the cabinet] was labelled" (CA13). Another carer thought that using many adaptations and devices would make the environment more complicated for the person with dementia, "I have thought about having a stair lift but that could be dangerous with him cause he wouldn't know how to work it" (CA10). Two carers had to return the equipment because they thought it was unsafe for their relative, and other carers identified such devices as symbols of disability and abnormality: "I try and keep it very basic and very normal, very normal for her. I think that is essential, I don't want her to feel she is an invalid" (CA11). 
3.2 Reluctance in involving professionals'. Ten carers expressed reservations about the involvement of health and social care professionals, believing that they will not offer adequate support, "I don't think the social worker has any idea about modifications, she's only a young girl" (CA01) or there will be a long wait, "it would take so long to come out to assess you" (CA03). Three carers were reluctant or did not even think about involving professionals, and implemented modifications themselves through trial and error.

3.3 Property spatial characteristics. Carers thought that there were two limitations within their home environment preventing them from implementing environmental strategies: home ownership and size. In the first case, two carers perceived that rental accommodation to be a restriction criterion: “This isn't our flat, so... I would have it different all together... I don't want to spend money on somebody else's property... I may not be here much longer" (CA01). In the second case, for four carers a small space meant that they had no room for adaptations: “Things I would like [to change] but there, but I can't do it because there's no room so" (CA03).

3.4 Financial reasons. Another barrier was the financial costs involved in implementing adaptations. This was mentioned both by one carer who owned their property and those two who did not: "After he had had a fall I did think that maybe I ought to think about it [nonslip flooring], but knowing how expensive it is, I haven't done anything at the moment" (CA13).

3.5 Timing. The last limitation was the timing of adaptations in relation to the progress of the dementia. Three carers thought that changes and equipment is best introduced early on to prevent further confusion. In two cases, the person with dementia did not recognise devices as familiar items: “They’ve kindly supplied a commode but he won't use it... because I've introduced it too late in the illness" (CA10). On the other hand, three carers thought that adaptations and devices are needed in a later stage. "We don't feel that we need 
them [alarms]... If she deteriorates, then we will come to that decision, if she deteriorates more but, at the moment, [we are] quite happy with what we got" (CA08).

The participants varied in their responses and the barriers they identified. Only one participant identified one of the above-mentioned barriers, six mentioned a couple of them, five mentioned three, and one carer mentioned four of them. Reluctance in involving the professionals was identified by ten carers, followed by the timing, scepticism over the importance of the environment, the property's spatial characteristics and lastly the financial restrictions.

\section{Discussion}

This study gathered empirical evidence on all aspects of the home environment and utilised indoor walking interviews with family carers of people with dementia. In line with previous research, our findings indicate that the size, condition, layout and accessibility of the property are important for the carers, (Bentley et al., 1985; de la Cuesta \& Sandelowski, 2005; Lach \& Chang, 2007; Olsen et al., 1999). However, the present study also shows that the carers identified the proximity of rooms as another important factor for accessibility and observation to facilitate navigation and manage care.

Regarding the architectural elements, we found that the size of the property is crucial for providing space for equipment, appliances, and 'escape' space(s) for the carers. Although, for the majority of the carers, bigger properties were regarded as more suitable, two of the carers had moved to one-bedroom apartments because they were more handy and manageable. However, this can only be achievable in practice for caring relatives, who still share the same bedroom. Previous research indicated that space for 'escape' and privacy are preferable in living well with dementia (Gitlin, 2007; Soilemezi, Drahota, Crossland, \& 
Stores, 2017; van Hoof \& Kort, 2009; Van Steenwinkel, Van Audenhove, \& Heylighen, 2017).

In general, an open layout allowing visual and acoustic connectivity, appeared to be preferable, although some participants disagreed. Previous research also offers mixed evidence about an open layout (Marquardt, Johnston, Black, Morrison, Rosenblatt, Lykentsos, et al., 2011a; Olsen et al., 1999; van Hoof \& Kort, 2009). The presence of stairs was considered a reason for relocation for two carers, while a stair-free home was considered a facilitator by all but one of the carers, which echoes previous studies (Bigonnesse, Beaulieu, \& Garon, 2014; Gill, Williams, Robison, \& Tinietti, 1999; Marquardt, Johnston, Black, Morrison, Rosenblatt, Lyketsos, et al., 2011b; Safran-Norton, 2010). Access to areas, for example a toilet in each level, was perceived as very helpful to minimise night wandering (and thus reduce risk of falls and incontinence accidents). Previous research has also indicated that windows and adequate lighting are important for people with dementia to enhance safety and wellbeing (Torrington \& Tregenza, 2007; Wong et al., 2014), to provide time and season orientation (van Hoof \& Kort, 2009) and contributing to the feeling of them less isolated or trapped (De Witt, Ploeg, \& Black, 2009; Gibson, Chalfont, Clarke, Torrington, \& Sixsmith, 2007), but our findings highlighted the presence of big windows, pleasing views and brightness as important aspects also for carers. This of course depends on the surroundings outside, which in densely populated areas, may be problematic due to noise and the feeling of exposure.

The location and proximity of the rooms was another significant finding of this study. Figures $11 \& 12$ represent the adjacencies of two of the dwellings (floor plans $1 \& 2$ showed in Figures $1 \& 2$ ) that despite their possible disadvantages include a lot of positive elements. The first figure represents a two-level house and the second a single-level apartment, showing the issues raised by the interviewees. While architects and designers do not have control over 
the size of the dwelling or environment, they have the tools to define the immediate environment. As shown in Figure 12, although there are most of the desired adjacencies (toilets on both levels, visual connections in the main room, ability to control the stair, a garden for views and escape), the space sets a series of obstacles (i.e. small changes of levels that may cause accidents), small windows limit the natural light in the living spaces, elements that designers could have avoided. On the other hand, Figure 11 presents a more easily controlled space, where even with the lack of visual connections, things can be resolved through the use of technologies.

Regarding the interior home environment, familiarity was found to be important for family carers to reduce their relatives' confusion and hence their caring demands.

Conversely, unfamiliarity can be a useful strategy for carers when they need to prevent risks, for example installing a new oven that is unfamiliar so that the person with dementia is less likely to operate it. As a part of maintaining familiarity, carers reported placing photographs, favourite furniture and personal objects around their home as a strategy against social isolation and a means to provide comfort, a sense of continuity and connectedness with their families. This strategy is also reported in previous research (de la Cuesta \& Sandelowski, 2005; Sixsmith et al., 2014; Swenson, 2010). Finally, our study confirms previous research indicating the importance of regulating thermal comfort inside home (van Hoof et al., 2010).

Carers adapted their home in a range of ways, from simply installing locks on cupboards to installing a walk-in shower, and using a number of equipment and devices. The majority of these changes were used to compensate for physical rather than cognitive difficulties. Although equipment was perceived as beneficial (even used by some of the carers), our findings showed a mixed reaction to assistive devices, with five carers reporting that they were essential in promoting safety, independence and a sense of control while six carers were more sceptical about their use and need. Arguably, the assistive devices may 
allow for time to be spent in personalised activities.

Organising, simplifying and re-arranging as well as establishing routines were widely used as strategies for reducing confusion and demand. In addition, a number of other strategies were reported as helpful, such as simple adjustments, visual strategies (such as written information and colour cues), hiding, disguising or removing items, controlling, which is also documented in previous studies with dementia carers (de la Cuesta \& Sandelowski, 2005; Donovan \& Corcoran, 2010; Redfern, Norman, Briggs, \& Askham, 2002). Reduction of noise was essential to support their relative, consistent with previous research that suggests that "noise is for people with dementia what stairs are to people in wheelchairs" (Judd, Marshall, \& Phippen, 1998; p.17). As expected, the carers utilised strategies based on sensory cues as memory prompts. Interestingly, only one carer reported colour as a useful strategy for highlighting objects, although previous research has suggested that the use of contrasting colour can be useful in dementia care (Mace \& Rabins, 2011).

The present study identified various reasons why carers did not implement environmental solutions: mainly carers' perceptions and expectations around the usability and need, mistrust in the support of professionals, timing, costs and property's characteristics. Routines and habits are difficult to change in older age (Dahlin-Ivanoff et al., 2007) and this may explain why some carers did not wish to try new adaptations. Another explanation could be that carers lacked information about the progress and symptoms of the illness, or lacked understanding of the potential impact of the environment on mood and behaviour and hence miss out a lot of available environmental solutions. Not realising the possible importance of the environment appears a major barrier to implementing potential solutions.

The cost of adaptations was identified as another barrier (see also Boger et al., 2013; Hawkins \& Stewart, 2002; Kinney, Kart, Murdoch, \& Ziemba, 2003; Lach \& Chang, 2007; Marquardt, Johnston, Black, Morrison, Rosenblatt, Lyketsos, et al., 2011b; Pierce et al., 
2015; Tanner et al., 2008). This is an important finding considering that dementia carers report higher levels of financial difficulties than other types of carers (Ory, Yee, Tennstedt, \& Schulz, 2000) and so more state support and services should be in place for them.

Another barrier to making home adaptations was due to property characteristics: space and ownership. Home ownership is considered important as it allows one to exert control over the immediate home environment and change, adapt or personalise it (Bentley et al., 1985; Dupuis \& Thorns, 1998). It has also been associated with healthy ageing and independence, but also as influencing one's identity and belonging (Després \& Lord, 2005; Després, 1991; Saunders, 1989; Shaw, 2004; Sixsmith et al., 2014; Swenson, 2010). Arguably, if a home environment is flexible and easily manipulated to accommodate for changing needs, ownership may no longer be a barrier.

Whether or not a property was rented or owned not only affected the amount of money spent on it, but also the perceived responsibility for making the necessary improvements or modifications. There is a crucial link here to the modernist concept of "the adaptable house," with moving walls and open plans, such as Rietveld's 1924 Schroeder house (Kolarevic, 2015), Archigram's 1967 Control and Choice project (Saddler, 2005) with the plug-in elements for customisation or more recently the Doug Jackson's DRAPE project (Jackson, 2009). Such houses adapt easily, without ownership being an issue anymore.

\section{Limitations}

This is a cross-sectional study and the data were derived from the perspectives of thirteen carers, all White, conveniently selected and heterogeneous in personal and housing conditions. All participants had already been involved with local services and had implemented minor or major adaptations. Therefore they were used to dealing with daily environmental challenges and accepting them. In some cases, adaptations were in place due 
to physical difficulties, before the relative was diagnosed with dementia. It is also possible that carers stopped using some of the reported strategies or introduced new ones. Thus, it is unlikely that strategies are applicable to all carers or to all stages and forms of dementia. Also, carers' perceptions of the researcher as an 'expert' may have influenced the level of disclosed information to 'impress' or satisfy the researcher.

\section{Implications for practitioners}

The issues addressed in this paper are relevant to practitioners in the construction industry (architects, interior designers and future housing developers) as well as health and social care professionals. In building sustainable housing, one ought to take into consideration the type and progression of illness, the environment and the inhabitants. Different types of dementia affect different capacities (memory, attention, speech, vision, mobility) and different carers face different challenges and circumstances. Housing developers need to understand the dynamic relationship between people and their homes and the need to live in flexible living spaces to accommodate changes over their lifetime with minimal possible cost, modifications and stress (Hawkins \& Stewart, 2002; Pierce et al., 2015). They have the great challenge to marry together several aspects that are perceived as important for older population (including carers of people with dementia), such as adequate size (with at least two bedrooms and spaces for escape), costs and location.

Architects need to carefully consider issues around the accessibility to important areas (e.g. bedroom, toilet, outside space), layout (preferably stair-free, toilet on each level), proximity (adjacency) of rooms (bathroom with the main bedroom, main bedroom with the second bedroom), as well as natural light. It is also important to understand the unique personal meanings and experiences of living and caring at home (Aminzadeh, Dalziel, 
Molnar, \& Garcia, 2010; Soilemezi, Drahota, Crossland, \& Stores, 2017) and build in spaces for escape. It is advisable to focus on a more proactive approach and design houses anticipating how things may change (e.g. children leaving home and ageing). It has also been suggested to incorporate permanent safety elements into the interior design of homes, so the next generation of people affected by dementia so that these will already be available to them, such as reversible doors or safety ovens (Nygård, 2009), as standard and familiar domestic elements. While the debate over closed versus open layout is ongoing, visual connectivity can be achieved even with the presence of physical barriers, for example with internal openings, windows, etc. In multi-level properties, the design of stairs is crucial for enabling safety and comfort. The presence of steep stairs was a reason for relocation and this is perhaps something that needs to be challenged and addressed by re-examining standards and current policies for domestic spaces - as staircases are a problem for both the person with dementia and the also ageing carer. In addition, there is also the choice of materials and details (e.g. smooth matt skirting, windows that can open inside) that can support the cleaning and maintaining of the property for ageing (and often exhausted) carers.

We found that carers often invent solutions and learn new skills without professional guidance or support. Perhaps the need for improvisations may indicate that current services do not meet carers' needs, because of the inflexibility of those services, bureaucracy, long waiting lists, busy workloads and lack of a follow-up evaluation. It could also be that carers are unaware of the available services, or even have negative perceptions about them. The carers in this study also believed that timing was important: too late and the adaptations may be ineffective, whereas too early and they might get rejected by the person with dementia. At the same time, health and social care professionals need to consider that often carers do not ask for support and practical suggestions in time. As a result, carers may invite professional help too late, only when they are too exhausted or an accident or crisis has occurred (Egset \& 
Myklebust, 2011; Lach \& Chang, 2007). Professionals therefore need to reach out to the carers and offer continuous needs assessment and support.

Modifications need to be in place as soon as a need arises to be effective (Nijhof, van Gemert-Pijnen, Burns, \& Seydel, 2013; Nygård, 2009; Petersson, Kottorp, Bergstrom, \& Lilja, 2009; Pynoos \& Ohta, 1991). Insufficient formal support can impact on the quality of caring and contribute to the decision to relocate the person to a more supportive setting (e.g. an easily accessible property, a warden controlled flat).

In addition, educating the carers in the role of the environment and available adaptations is required. Carers may not understand fully the impact of their environment and in some cases underreport environmental problems to services. This can be either because carers valued their home so highly and/or they might under-estimate some aspects due to 'over-familiarization' (Oswald \& Wahl, 2004), or lack information on the importance of the environment and/or available solutions. Carers might attribute any difficulties to themselves or their relative's condition and not necessarily to the home environment. Including family carers in the design and management of interventions is important as they have an influential role in the compliance to interventions and are a valuable source to identify even the subtle changes in their relative's function levels. Therefore, negotiated joint decisions and continuous assessment are needed to ensure the proposed solutions address everyone's needs and cause the least disruptions and restrictions.

\section{Future research}

As studies in private homes are very limited, more qualitative studies are needed to elicit the experiences and preferences of people with dementia and their carers at managing dementia at home (Carmody, Traynor, \& Marchetti, 2014; Prince, Prina, \& Guerchet, 2013). Studies should utilise heterogeneous and cross-cultural samples in a longitudinal design to 
capture possible changes over time and bring more insight to the importance of home and environmental interventions for dementia care. In addition, examining all the residents' needs could bring more light on whether there are competing meanings and experiences from the perspectives of the person with dementia and the carer, in order to reinforce the meaning of and interactions with the home for the dyad. More research on home environments is essential to better understand which environmental features and strategies are effective and perceived as helpful to different forms of dementia carers and at what stage, for example open plan versus closed rooms layout or flexible space arrangements. Eight carers in this study clearly indicated that an open-plan layout was helpful, whereas only four favoured the option of closed off areas. The research into home environments has the potential to close the gap between theory-research-application and could contribute to clinical applications and inform future housing design (Gitlin, 2003). Naturalistic data collection methods, such as walking interviews and home observations, allow the researcher to be exposed to the reality of the participants and add validity to the findings. Interviewing people around their homes helps recall specific issues and facilitates a more detailed account of experiences and concerns (Wherton \& Monk, 2008).

\section{Conclusion}

This study explored the experiences and views of co-resident family carers of people with dementia regarding the role of their home environment. The findings illuminated a number of important architectural and design aspects, such as size, layout and condition of the property, familiarity, brightness, flooring, and the acoustic, olfactory and thermal environment. Family carers implemented a wide range of strategies to tackle daily safety 
challenges, and promote autonomy and comfort at home. Often carers adapted their home through trial and error, without expert advice. Barriers to implementing adaptations concerned the carers' scepticism over the use and need of such interventions, mistrust towards practitioners, financial difficulties, timing and spatial restrictions. In addressing dementia care, there is no universal solution to satisfy carers' needs. Environmental manipulation is not a panacea but is a simple and often inexpensive approach that can offer the opportunity to a person with dementia and carers to live in a safe and comfortable environment. 


\section{References}

Aminzadeh, F., Dalziel, W. B., Molnar, F. J., \& Garcia, L. J. (2010). Meanings, functions, and experiences of living at home for individuals with dementia at the critical point of relocation. Journal of Gerontological Nursing, 36(6), 28-35.

http://doi.org/10.3928/00989134-20100303-02

Bentley, I., Alcock, A., Murrain, P., McGlynn, S., \& Smith, G. (1985). Responsive environments. A manual for designers. UK: Routledge.

Bigonnesse, C., Beaulieu, M., \& Garon, S. (2014). Meaning of home in later life as a concept to understand older adults' housing needs: Results from the 7 age-friendly cities pilot project in Québec. Journal of Housing For the Elderly, 28(4), 357-382. http://doi.org/10.1080/02763893.2014.930367

Boger, J., Quraishi, M., Turcotte, N., \& Dunal, L. (2013). The identification of assistive technologies being used to support the daily occupations of community-dwelling older adults with dementia: a cross-sectional pilot study. Disability \& Rehabilitation: Assistive Technology, 9(1), 17-30. http://doi.org/10.3109/17483107.2013.785035

Braun, V., \& Clarke, V. (2006). Using thematic analysis in psychology. Qualitative Research in Psychology, 3(2), 77-101. http://doi.org/10.1191/1478088706qp063oa

Brawley, E. C. (2001). Environmental design for Alzheimer's disease: a quality of life issue. Aging and Mental Health, 5(2), 79-83. http://doi.org/10.1080/13607860120044846

Calkins, M. P., \& Namazi, K. H. (1991). Caregivers' perceptions of the effectiveness of home modifications for community living adults with dementia. American Journal of Alzheimer's Disease and Other Dementias, 6(1), 25-29. http://doi.org/10.1177/153331759100600106

Carmody, J., Traynor, V., \& Marchetti, E. (2014). Barriers to qualitative dementia research: The elephant in the room. Qualitative Health Research, 25(7), 1013-1019. 
http://doi.org/10.1177/1049732314554099

Carpiano, R. M. (2009). Come take a walk with me: the "go-along" interview as a novel method for studying the implications of place for health and well-being. Health \& Place, 15(1), 263-72. http://doi.org/10.1016/j.healthplace.2008.05.003

Corcoran, M., \& Gitlin, L. N. (1991). Environmental influences on behavior of the elderly with dementia: principles for intervention in the home. Physical \& Occupational Therapy in Geriatrics, 9(3/4), 5-22. http://doi.org/10.1080/J148V09N03_02

Dahlin-Ivanoff, S., Haak, M., Fänge, A., \& Iwarsson, S. (2007). The multiple meaning of home as experienced by very old Swedish people. Scandinavian Journal of Occupational Therapy, 14(1), 25-32. http://doi.org/10.1080/11038120601151714

Day, K., Carreon, D., \& Stump, C. (2000). The therapeutic design of environments for people with dementia: a review of the empirical research. The Gerontologist, 40(4), 397-416. http://doi.org/10.1093/geront/40.4.397

de la Cuesta, C., \& Sandelowski, M. (2005). Tenerlos en la casa: The material world and craft of family caregiving for relatives with dementia. Journal of Transcultural Nursing, 16(3), 218-225. http://doi.org/10.1177/1043659605274979

De Witt, L., Ploeg, J., \& Black, M. (2009). Living on the threshold: The spatial experience of living alone with dementia. Dementia, 8(2), 263-291. http://doi.org/10.1177/1471301209103273

Després, C. (1991). The meaning of home: Literature review and directions for future research and theoretical development. The Journal of Architectural and Planning Research, 8(2), 96-115. Retrieved from http://www.jstor.org/stable/43029026

Després, C., \& Lord, S. (2005). Growing older in postwar suburbs: The meanings and experiences of home. In G. D. Rowles \& H. Chaudhury (Eds.), Home and Identity in Late Life (pp. 317-340). Springer Publishing Co. 
Donovan, M. L., \& Corcoran, M. (2010). Description of dementia caregiver uplifts and implications for occupational therapy. American Journal of Occupational Therapy, 64(4), 590-595. http://doi.org/10.5014/ajot.2010.09064

Dupuis, A., \& Thorns, D. (1998). Home, home ownership and the search for ontological security. The Sociological Review, 46, 24-47. Retrieved from http://onlinelibrary.wiley.com/doi/10.1111/1467-954X.00088/abstract

Egset, A. S., \& Myklebust, J. O. (2011). Dementia in the family: Two Norwegian case studies. Dementia, 10(4), 571-585. http://doi.org/10.1177/1471301211415315

Evans, J., \& Jones, P. (2011). The walking interview: Methodology, mobility and place. Applied Geography, 31(2), 849-858. http://doi.org/10.1016/j.apgeog.2010.09.005

Garcia, L. J., Kartolo, A., \& Méthot-Curtis, E. (2012). A discussion of the use of virtual reality in dementia. In C. Eichenberg (Ed.), Virtual Reality in Psychological, Medical and Pedagogical Applications (pp. 123-136). Intech.

Gibson, G., Chalfont, G. E., Clarke, P. D., Torrington, J. M., \& Sixsmith, A. J. (2007). Housing and connection to nature for people with dementia: findings from the INDEPENDENT project. Journal of Housing for the Elderly, 21(1-2), 55-72. http://doi.org/10.1300/J081v21n01_04

Gill, T. M., Williams, C. S., Robison, J. T., \& Tinietti, M. E. (1999). A population-based study of environmental hazards in the homes of older persons. American Journal of Public Health, 89(4), 553-556. Retrieved from http://www.ncbi.nlm.nih.gov/pmc/articles/PMC1508891/

Gitlin, L. N. (2003). Conducting research on home environments: lessons learned and new directions. The Gerontologist, 43(5), 628-37. http://doi.org/10.1093/geront/43.5.628

Gitlin, L. N. (2007). Guidelines for environmental adaptations and safety at home. Alzheimer's Care Today, 8(3), 278-281. Retrieved from 
http://search.ebscohost.com/login.aspx?direct=true \&db=cin20\&AN=2010202920\&site= ehost-live

Gitlin, L. N., Hodgson, N., Piersol, C. V., Hess, E., \& Hauck, W. W. (2013). Correlates of quality of life for individuals with dementia living at home: The role of home environment, caregiver, and patient-related characteristics. The American Journal of Geriatric Psychiatry, 22(6), 587-597. http://doi.org/10.1016/j.jagp.2012.11.005

Gitlin, L. N., Liebman, J. M., \& Winter, L. (2003). Are environmental interventions effective in the management of Alzheimer's disease and related disorders?: A synthesis of the evidence. Alzheimer's Care Quarterly, 4(2), 85-107. Retrieved from http://journals.lww.com/actjournalonline/Abstract/2003/04000/Are_Environmental_Inte rventions_Effective_in_the.3.aspx

Gitlin, L. N., Marx, K., Stanley, I. H., \& Hodgson, N. (2015). Translating evidence-based dementia caregiving interventions into practice: State-of-the-Science and next steps. The Gerontologist, 55(2), 210-226. http://doi.org/10.1093/geront/gnu123

Golant, S. M. (2015). Aging in the right place. Baltimore, MD: Health Professions Press.

Graff, M. J. L., Adang, E. M. M., Vernooij-Dassen, M. J. M., Dekker, J., Jönsson, L., Thijssen, M., ... Rikkert, M. G. M. O. (2008). Community occupational therapy for older patients with dementia and their care givers: cost effectiveness study. $B M J$, 336(134), 1-9. http://doi.org/10.1136/bmj.39408.481898.BE

Graff, M. J. L., Vernooij-Dassen, M. J. M., Thijssen, M., Dekker, J., Hoefnagels, W. H. L., \& Rikkert, M. G. M. O. (2006). Community based occupational therapy for patients with dementia and their care givers: randomised controlled trial. BMJ (Clinical Research Ed.), 333(7580), 1196. http://doi.org/10.1136/bmj.39001.688843.BE

Habell, M. (2010). The dementia care building crisis. Perspectives in Public Health, 130(3), 110-110. http://doi.org/10.1177/1757913910365249

URL: http://mc.manuscriptcentral.com/wjhe Email: SchwarzB@@missouri.edu 
Hawkins, R., \& Stewart, S. (2002). Changing rooms: the impact of adaptations on the meaning of home for a disabled person and the role of occupational therapists in the process. British Journal of Occupational Therapy, 65(2), 81-87. http://doi.org/10.1177/030802260206500206

Jackson, D. (2009). Wiki-tecture: the DRAPE artist residence and gallery. Journal of Architectural Education, 63(1), 97-106.

Judd, S., Marshall, M., \& Phippen, P. (1998). Design for Dementia. London: Hawker Publications.

Kahana, E., Lovegreen, L., Kahana, B., \& Kahana, M. (2003). Person, environment, and person-environment fit as influences on residential satisafaction of elders. Environment and Behavior, 35(3), 434-453. http://doi.org/10.1177/0013916503035003007

Kaplan, D. B., Andersen, T. C., Lehning, A. J., \& Perry, T. E. (2015). Aging in Place vs. Relocation for Older Adults with Neurocognitive Disorder: Applications of Wiseman's Behavioral Model. Journal of Gerontological Social Work, (July), 1-18. http://doi.org/10.1080/01634372.2015.1052175

Kinney, J. M., Kart, C. S., Murdoch, L. D., \& Ziemba, T. F. (2003). Challenges in caregiving and creative solutions: Using technology to facilitate caring for a relative with dementia. Ageing International, 28(3), 295-314. http://doi.org/10.1007/s12126-002-1009-x

Kolarevic, B. (2015). Towards architecture of change. In B. Kolarevic \& V. Parlac (Eds.), Building dynamics: exploring architecture of change (pp. 1-295). Oxon: Taylor \& Francis.

Lach, H. W., \& Chang, Y.-P. (2007). Caregiver perspectives on safety in home dementia care. Western Journal of Nursing Research, 29(8), 993-1014. Retrieved from http://www.ncbi.nlm.nih.gov/pubmed/17630389

Lawton, M. P. (1990). Residential environment and self-directedness among older people. 
American Psychologist, 45(5), 638-640. http://doi.org/10.1037/0003-066X.45.5.638

Lawton, M. P. (1997). An ecological theory of aging applied to elderly housing. Environments and Aging, 31(1), 8-10. Retrieved from http://www.jstor.org/stable/1424527

Mace, N. L., \& Rabins, P. V. (2011). The 36-Hour Day. A family guide to caring for people who have Alzheimer disease, related dementias, and memory loss (5th ed.). Baltimore, MD: Johns Hopkins University Press.

Marquardt, G., Johnston, D., Black, B. S., Morrison, A., Rosenblatt, A., Lykentsos, C., \& Samus, Q. M. (2011). Association of the spatial layout of the home and ADL abilities among older adults with dementia. Journal Of Alzheimers Disease and Other Denetias, 26(1), 51-57. http://doi.org/10.1177/1533317510387584.Association

Marquardt, G., Johnston, D., Black, B. S., Morrison, A., Rosenblatt, A., Lyketsos, C., \& Samus, Q. M. (2011). A Descriptive Study of Home Modifications for People with Dementia and Barriers to Implementation. Journal of Housing for the Elderly, 25(3), 258-273. http://doi.org/10.1080/02763893.2011.595612

Messecar, D. C., Archbold, P. G., Stewart, B. J., \& Kirschling, J. (2002). Home environmental modification strategies used by caregivers of elders. Research in Nursing \& Health, 25(5), 357-70. http://doi.org/10.1002/nur.10048

Nijhof, N., van Gemert-Pijnen, J. E. W. C., Burns, C. M., \& Seydel, E. R. (2013). A personal assistant for dementia to stay at home safe at reduced cost. Gerontechnology, 11(3), 469-479. http://doi.org/10.4017/gt.2013.11.3.005.00

Olsen, R. V, Hutchings, B. L., \& Ehrenkrantz, E. (1999). The physical design of the home as a caregiving support: an environment for persons with dementia. Care Management Journals, 1(2), 125-131. Retrieved from http://www.ncbi.nlm.nih.gov/pubmed/10644296

URL: http://mc.manuscriptcentral.com/wjhe Email: SchwarzB@@missouri.edu 
Ory, M. G., Yee, J. L., Tennstedt, S. L., \& Schulz, R. (2000). The extent and impact of dementia care: Unique challenges experienced by family caregivers. In R. Schulz (Ed.), Handbook on dementia caregiving: Evidence-based interventions for family caregivers. (pp. 1-32). NY US: Springer.

Oswald, F., \& Wahl, H.-W. (2004). Housing and health in later life. Reviews on Environmental Health. Retrieved from http://www.psychologie.uniheidelberg.de/ae/apa/pdf/literatur/fo_housinghealth.pdf

Perry, T. E., Andersen, T. C., \& Kaplan, D. B. (2014). Relocation remembered: perspectives on senior transitions in the living environment. The Gerontologist, 54(1), 75-81. http://doi.org/10.1093/geront/gnt070

Petersson, I., Kottorp, A., Bergstrom, J., \& Lilja, M. (2009). Longitudinal changes in everyday life after home modifications for people aging with disabilities. Scandinavian Journal of Occupational Therapy, 16(2), 78-87.

http://doi.org/10.1080/11038120802409747.

Pierce, M., Cahill, S., Grey, T., \& Dyer, M. (2015). Research for dementia and home design in Ireland looking at new build and retro-fit homes from a universal design approach: key findings and recommendations report 2015. Dublin: Centre for Excellence in Universal Design.

Prince, M., Prina, M., \& Guerchet, M. (2013). World Alzheimer Report 2013 - Journey of Caring -An Analysis of long-term care for dementia. London: Alzheimer's Disease International (ADI).

Pynoos, J., \& Ohta, R. J. (1991). In-home interventions for persons with Alzheimer's disease and their caregivers. Physical \& Occupational Therapy in Geriatrics, 9(3-4), 83-92. http://doi.org/10.1080/J148V09N03_07

Pynoos, J., Steinman, B. A., Do Nguyen, A. Q., \& Bressette, M. (2012). Assessing and 
adapting the home environment to reduce falls and meet the changing capacity of older adults. Journal of Housing for the Elderly, 26(1-3), 137-155. http://doi.org/10.1080/02763893.2012.673382

Redfern, S., Norman, I., Briggs, K., \& Askham, J. (2002). Care at home for people with dementia: routines, control and care goals. Quality in Ageing, 3(4), 12-23. http://doi.org/http://dx.doi.org/10.1108/14717794200200023

Robinson, L., Hutchings, D., Dickinson, H. O., Corner, L., Beyer, F., Finch, T., ... Bond, J. (2007). Effectiveness and acceptability of non-pharmacological interventions to reduce wandering in dementia : a systematic review. International Journal of Geriatric Psychiatry, 22, 9-22. http://doi.org/10.1002/gps

Saddler, S. (2005). Archigram: architecture without architecture. Cambridge, MA US: MIT Press.

Sadowsky, C. H., \& Galvin, J. E. (2012). Guidelines for the management of cognitive and behavioral problems in dementia. Journal of the American Board of Family Medicine, 25(3), 350-66. http://doi.org/10.3122/jabfm.2012.03.100183

Safran-Norton, C. E. (2010). Physical home environment as a determinant of aging in place for different types of elderly households. Journal of Housing for the Elderly, 24(2), 208231. http://doi.org/10.1080/02763891003757494

Saunders, P. (1989). The meaning of "home" in contemporary english culture. Housing Studies, 4(3), 177-192. http://doi.org/10.1080/02673038908720658

Shaw, M. (2004). Housing and public health. Annual Review of Public Health, 25, 397-418. http://doi.org/10.1146/annurev.publhealth.25.101802.123036

Sixsmith, J., Sixsmith, A., Fänge, M. A., Naumann, D., Kucsera, C., Tomsone, S., ... Woolrych, R. (2014). Healthy ageing and home: the perspectives of very old people in five European countries. Social Science \& Medicine (1982), 106, 1-9.

URL: http://mc.manuscriptcentral.com/wjhe Email: SchwarzB@@missouri.edu 
http://doi.org/10.1016/j.socscimed.2014.01.006

Soilemezi, D., Drahota, A., Crossland, J., \& Stores, R. (2017). The role of the home environment in dementia care and support: Systematic review of qualitative research. Dementia, O(0), 1-36. http://doi.org/10.1177/1471301217692130

Soilemezi, D., Drahota, A., Crossland, J., Stores, R., \& Costall, A. (2017). Exploring the meaning of home for family caregivers of people with dementia. Journal of Environmental Psychology, 51, 70-81. http://doi.org/10.1016/j.jenvp.2017.03.007

Swenson, M. M. (2010). The meaning of home to five elderly women. Health Care for Women International, 19(5), 381-393. http://doi.org/10.1080/073993398246160

Tanner, B., Tilse, C., \& de Jonge, D. (2008). Restoring and sustaining home: The impact of home modifications on the meaning of home for older people. Journal of Housing For the Elderly, 22(3), 195-215. http://doi.org/10.1080/02763890802232048

Torrington, J. M., \& Tregenza, P. R. (2007). Lighting for people with dementia. Lighting Research and Technology, 39(1), 81-97. http://doi.org/10.1177/1365782806074484

Torti, F. M., Gwyther, L. P., Reed, S. D., Friedman, J. Y., \& Schulman, K. A. (2004). A multinational review of recent trends and reports in dementia caregiver burden. Alzheimer Disease and Associated Disorders, 18(2), 99-109. Retrieved from http://www.ncbi.nlm.nih.gov/pubmed/15249854

van Hoof, J., \& Kort, H. S. M. (2009). Supportive living environments: a first concept of a dwelling designed for older adults with dementia. Dementia, 8(2), 293-316. http://doi.org/10.1177/1471301209103276

van Hoof, J., Kort, H. S. M., Hensen, J. L. M., Duijnstee, M. S. H., \& Rutten, P. G. S. (2010). Thermal comfort and the integrated design of homes for older people with dementia. Building and Environment, 45(2), 358-370. http://doi.org/10.1016/j.buildenv.2009.06.013 
van Hoof, J., Kort, H. S. M., van Waarde, H., \& Blom, M. M. (2010). Environmental interventions and the design of homes for older adults with dementia: an overview. American Journal of Alzheimer's Disease and Other Dementias, 25(3), 202-32. http://doi.org/10.1177/1533317509358885

Van Steenwinkel, I., Van Audenhove, C., \& Heylighen, A. (2017). Offering architects insights into experiences of living with dementia: A case study on orientation in space, time and identity. Dementia, 1-15. http://doi.org/10.1177/1471301217692905

Wherton, J. P., \& Monk, A. F. (2008, August). Technological opportunities for supporting people with dementia who are living at home. http://doi.org/10.1016/j.ijhcs.2008.03.001

Wisniewski, S. R., Belle, S. H., Marcus, S. M., Burgio, L. D., Coon, D. W., Burns, R., \& Schulz, R. (2003). The resources for enhancing Alzheimer's caregiver health (REACH): project design and baseline characteristics. Psychology and Aging, 18(3), 375-384. http://doi.org/10.1037/0882-7974.18.3.375.The

Wong, J. K.-W., Skitmore, M., Buys, L., \& Wang, K. (2014). The effects of the indoor environment of residential care homes on dementia suffers in Hong Kong: A critical incident technique approach. Building and Environment, 73, 32-39.

http://doi.org/10.1016/j.buildenv.2013.12.001

World Health Organisation. (2012). Dementia: a public health priority. Geneva.

Zarit, S. H., Gaugler, J. E., \& Jarrott, S. E. (1999). Useful services for families: research findings and directions. International Journal of Geriatric Psychiatry, 14(3), 165-77-81. http://doi.org/10.1002/(SICI)1099-1166(199903)14:3<165::AID-GPS966>3.0.CO;2-O

URL: http://mc.manuscriptcentral.com/wjhe Email: SchwarzB@@missouri.edu 
Table 1. Carers' characteristics $(N=13)$

\begin{tabular}{|c|c|}
\hline Characteristic & $N$ \\
\hline \multicolumn{2}{|l|}{ Sex } \\
\hline Male & 4 \\
\hline Female & 9 \\
\hline \multicolumn{2}{|l|}{ Age } \\
\hline $50-59$ & 1 \\
\hline $60-69$ & 8 \\
\hline $70-79$ & 3 \\
\hline $80-89$ & 1 \\
\hline \multicolumn{2}{|l|}{ Years of caring } \\
\hline $0-5$ & 10 \\
\hline $6-10$ & 3 \\
\hline \multicolumn{2}{|l|}{ Type of property } \\
\hline Flats & 3 \\
\hline \multicolumn{2}{|l|}{$(1-$ bed*: 2$)$} \\
\hline \multicolumn{2}{|l|}{ (2-bed:1) } \\
\hline Houses & 8 \\
\hline \multicolumn{2}{|l|}{ (2-bed: 1) } \\
\hline \multicolumn{2}{|l|}{ (3-bed: 5) } \\
\hline \multicolumn{2}{|l|}{ (4-bed: 2) } \\
\hline Maisonettes (3-bed) & 2 \\
\hline \multicolumn{2}{|l|}{ Duration of residence } \\
\hline $0-10$ & 6 \\
\hline $11-20$ & 2 \\
\hline $21-30$ & 1 \\
\hline $31+$ & 4 \\
\hline
\end{tabular}

*In the UK, the number of bedrooms is commonly used to refer to the size

property

URL: http://mc.manuscriptcentral.com/wjhe Email: SchwarzB@@missouri.edu 
Table 2. Main Themes And Subthemes

\begin{tabular}{|l|l|}
\hline Main Themes & Subthemes \\
\hline 1. Important environmental aspects & $\begin{array}{l}1.1 \text { Architectural elements } \\
1.2 \text { Interior design aspects }\end{array}$ \\
\hline 2. Adapting and improvising & $\begin{array}{l}2.1 \text { Additive and supplementing strategies } \\
2.2 \text { Transformative strategies }\end{array}$ \\
& 2.3 Subtractive and simplifying strategies \\
& 2.4 Behavioural and structuring strategies \\
& 3.1 Carer's scepticism \\
3. Barriers to implementing & 3.2 Professionals' involvement \\
environmental strategies & 3.3 Property characteristics \\
& 3.4 Financial reasons \\
& 3.5 Timing \\
\end{tabular}

URL: http://mc.manuscriptcentral.com/wjhe Email: SchwarzB@@missouri.edu 

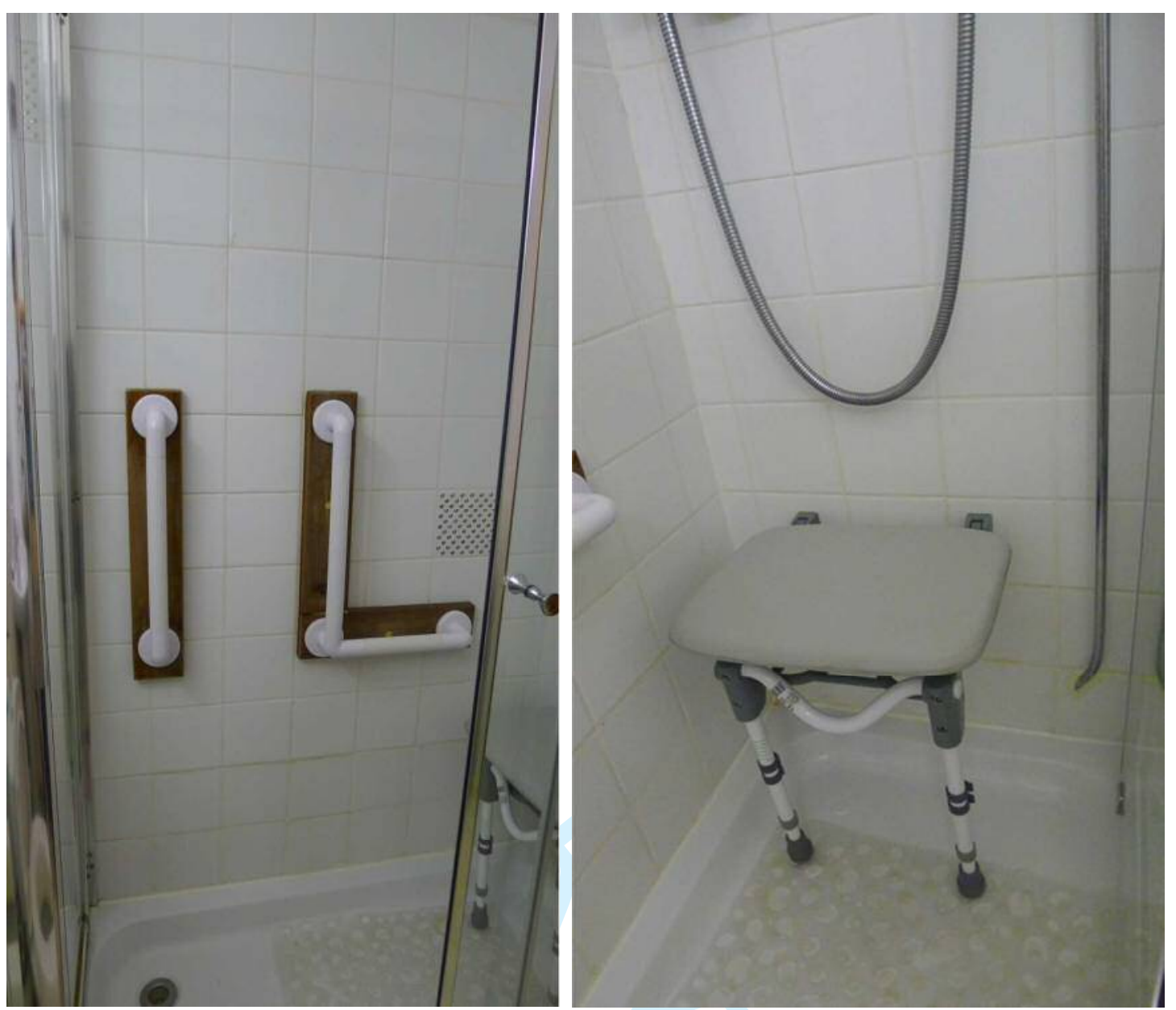

Figure 3: Grab rails installed in shower Photograph 4. Shower seat

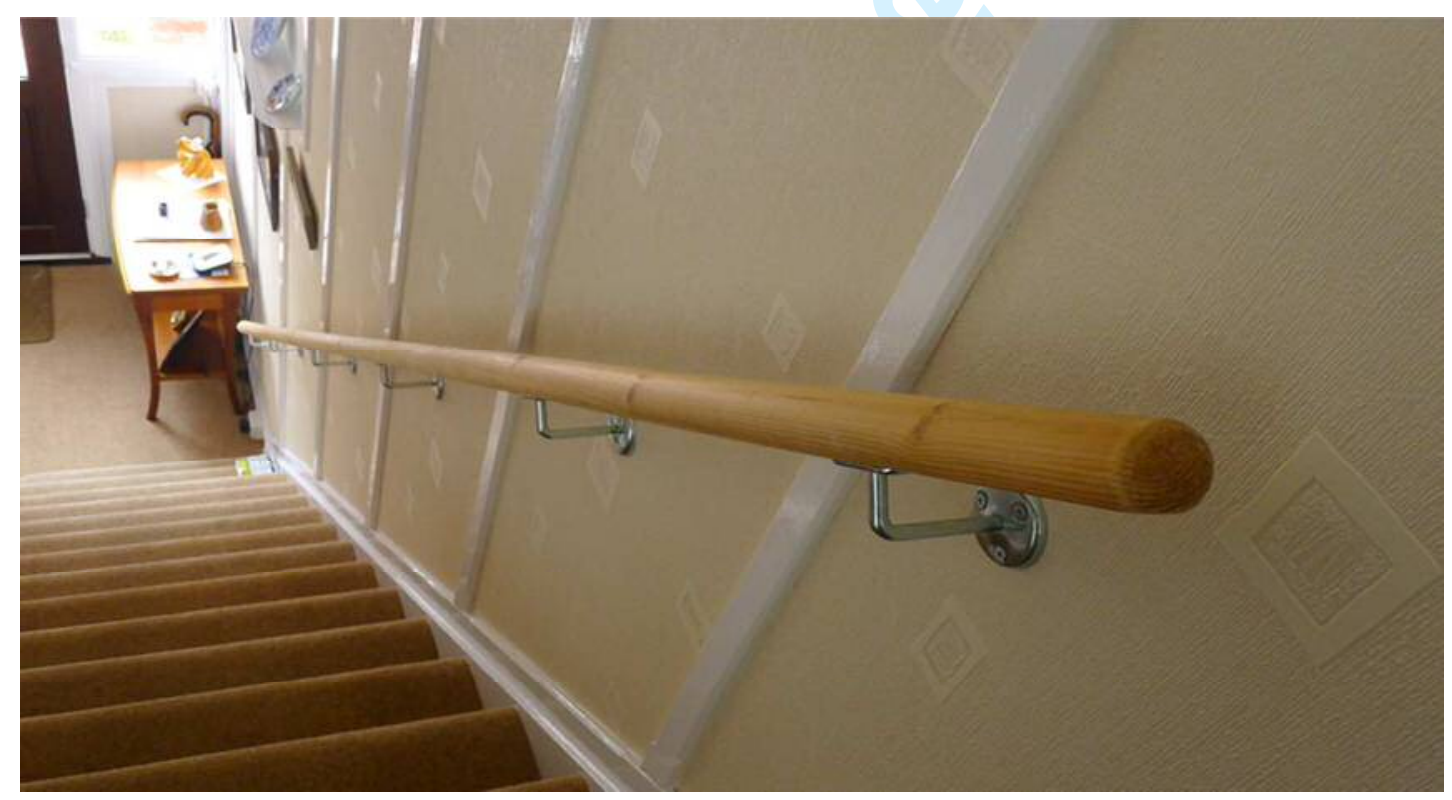

Figure 6. Banister installed along the stairs 


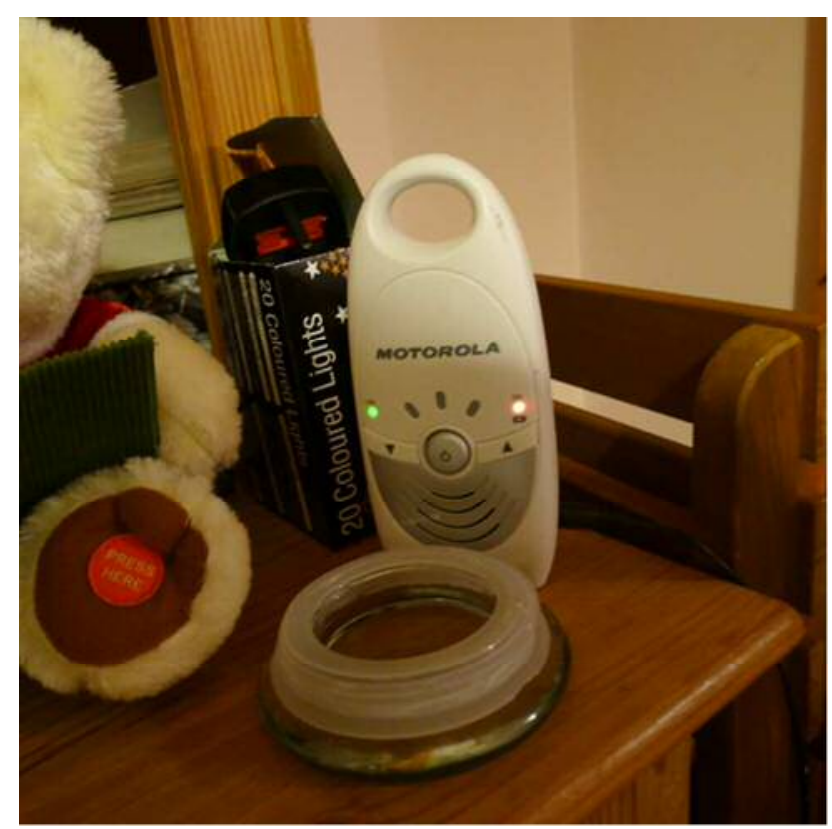

Figure 8. Baby monitor in the living room to alert carer

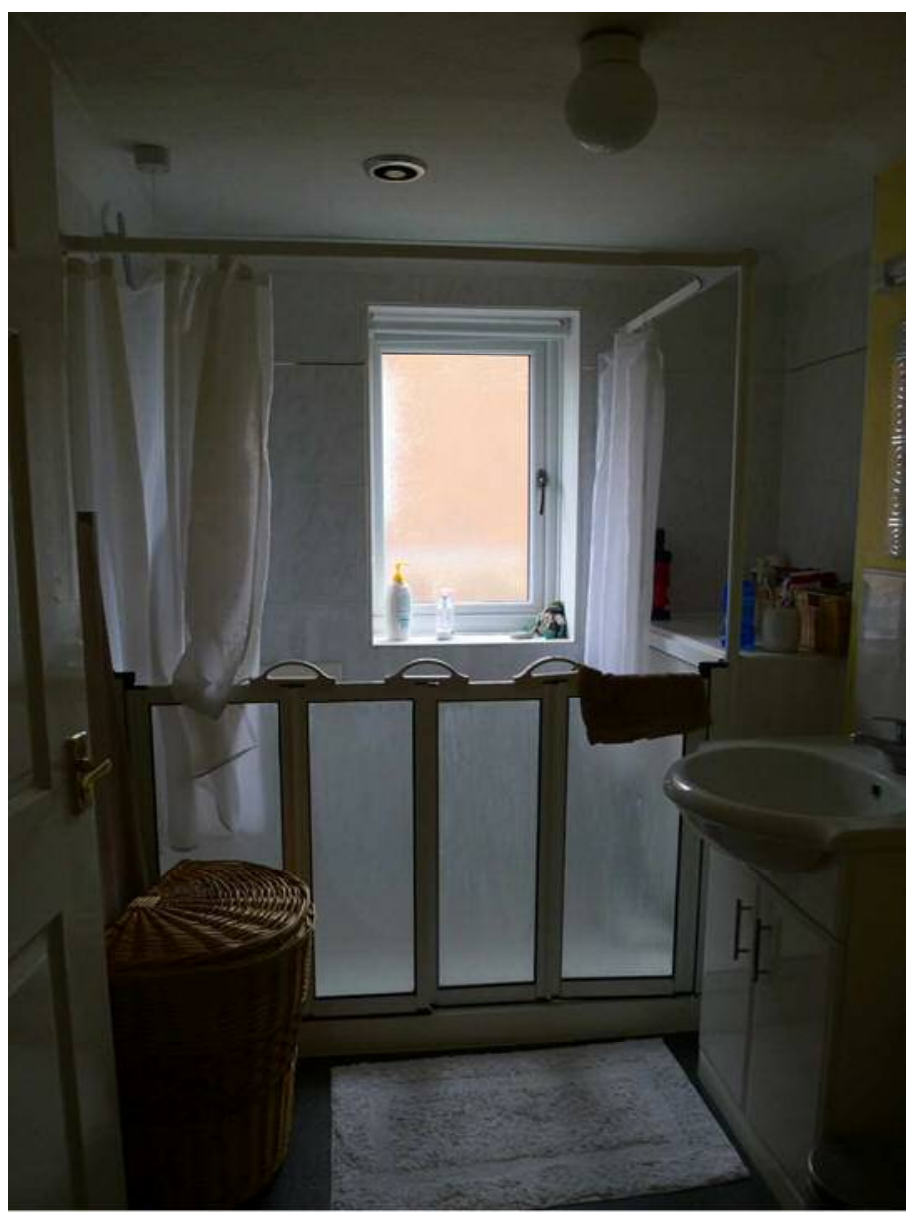

Figure 5 . Walk-in shower in the place of a bath 


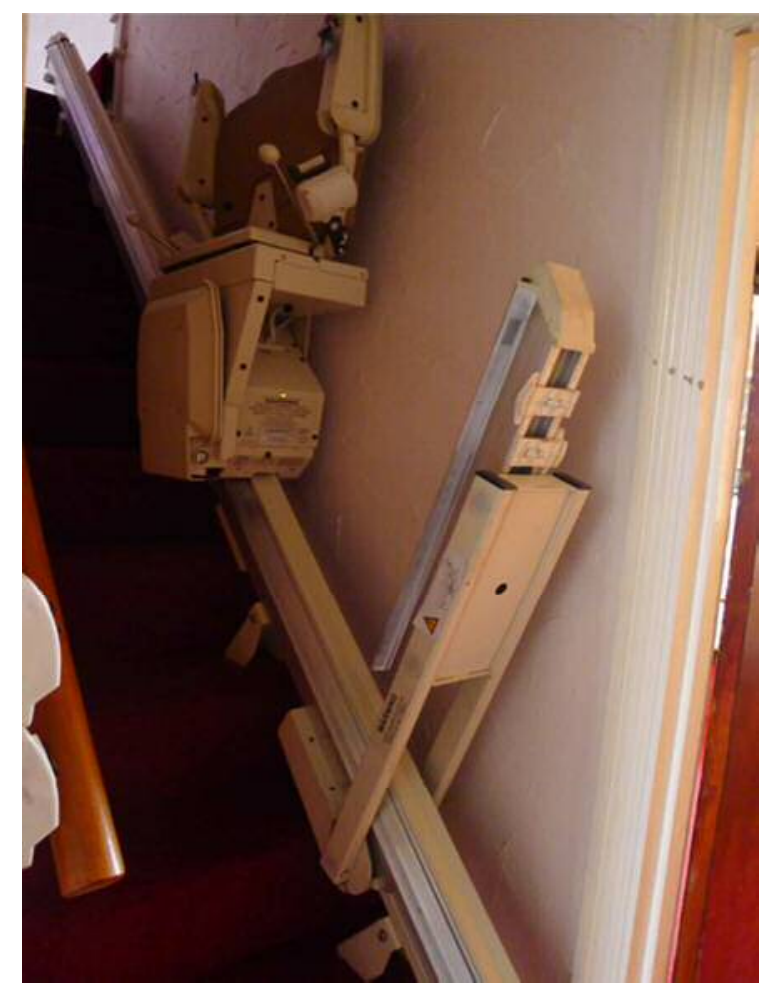

Figure 7. Stair lift

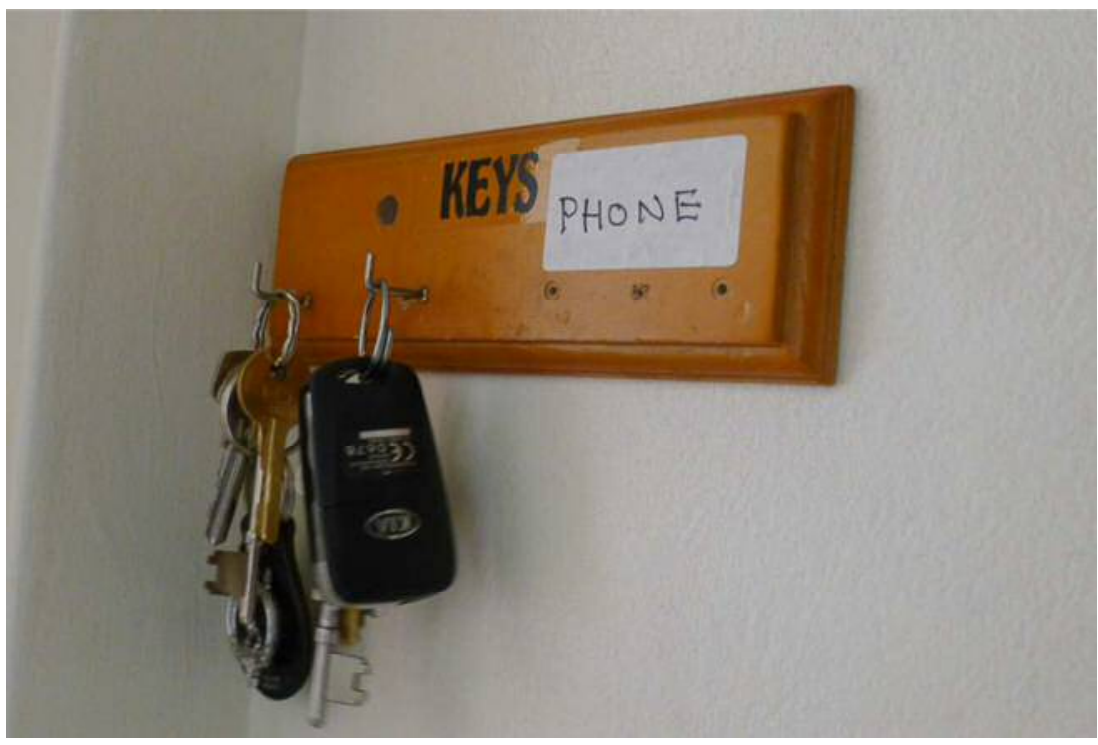

Figure 9. Providing visual cues 


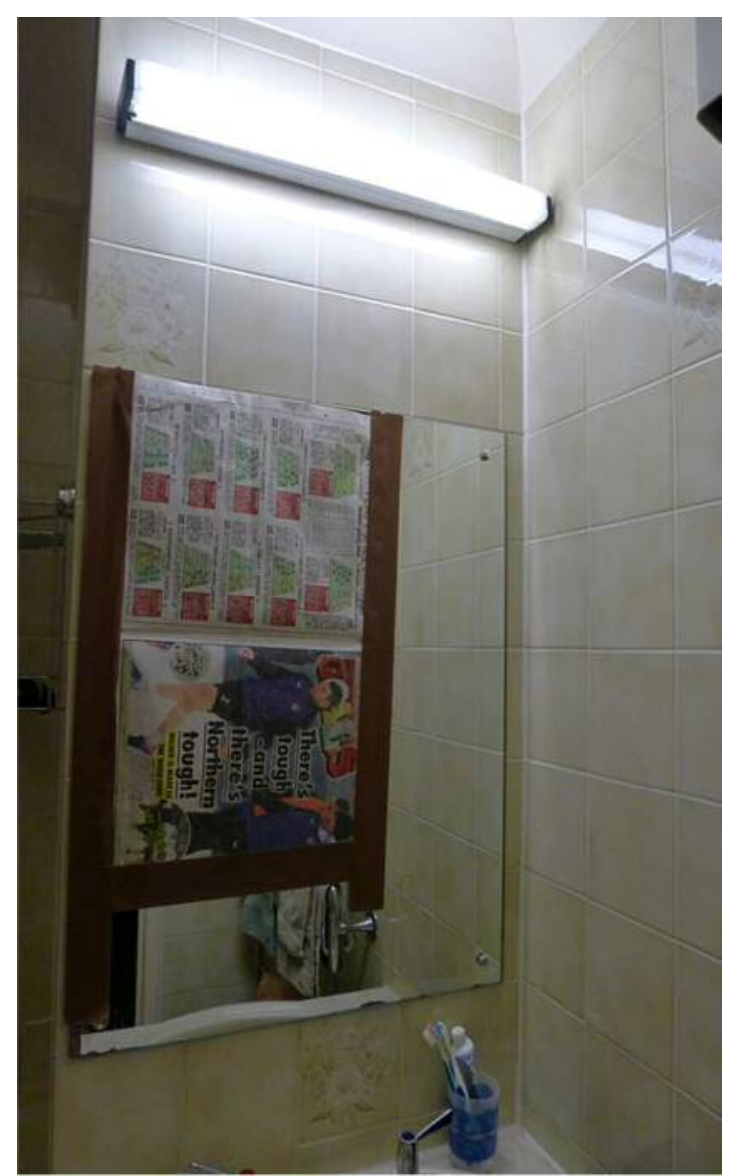

Figure 10. Covering the majority of the mirror as an environmental strategy 


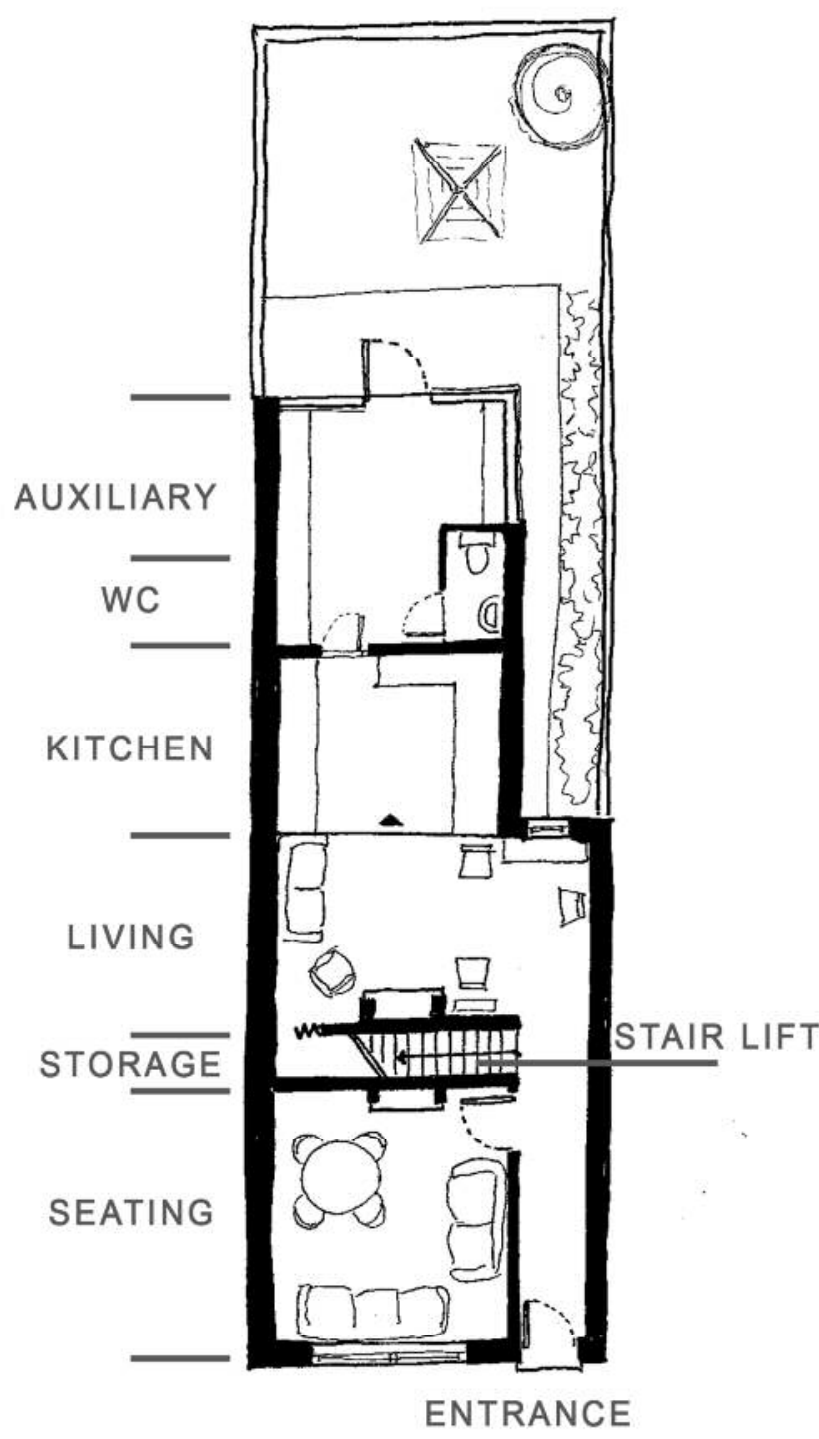

$126 \times 214 \mathrm{~mm}(300 \times 300 \mathrm{DPI})$ 


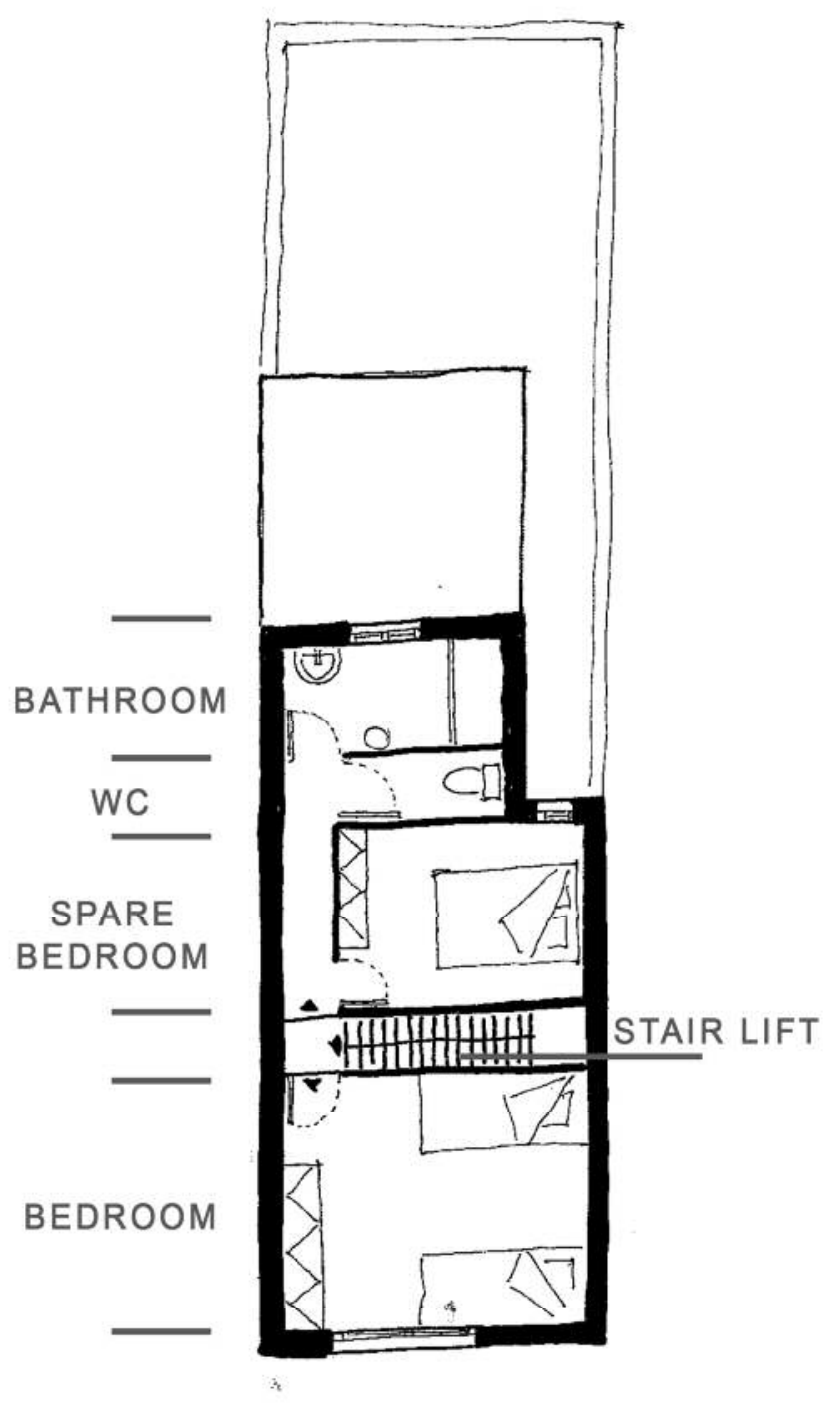

Figure 2a,b. Floor plan of a two-storey house (CA07) $126 \times 214 \mathrm{~mm}(300 \times 300 \mathrm{DPI})$ 


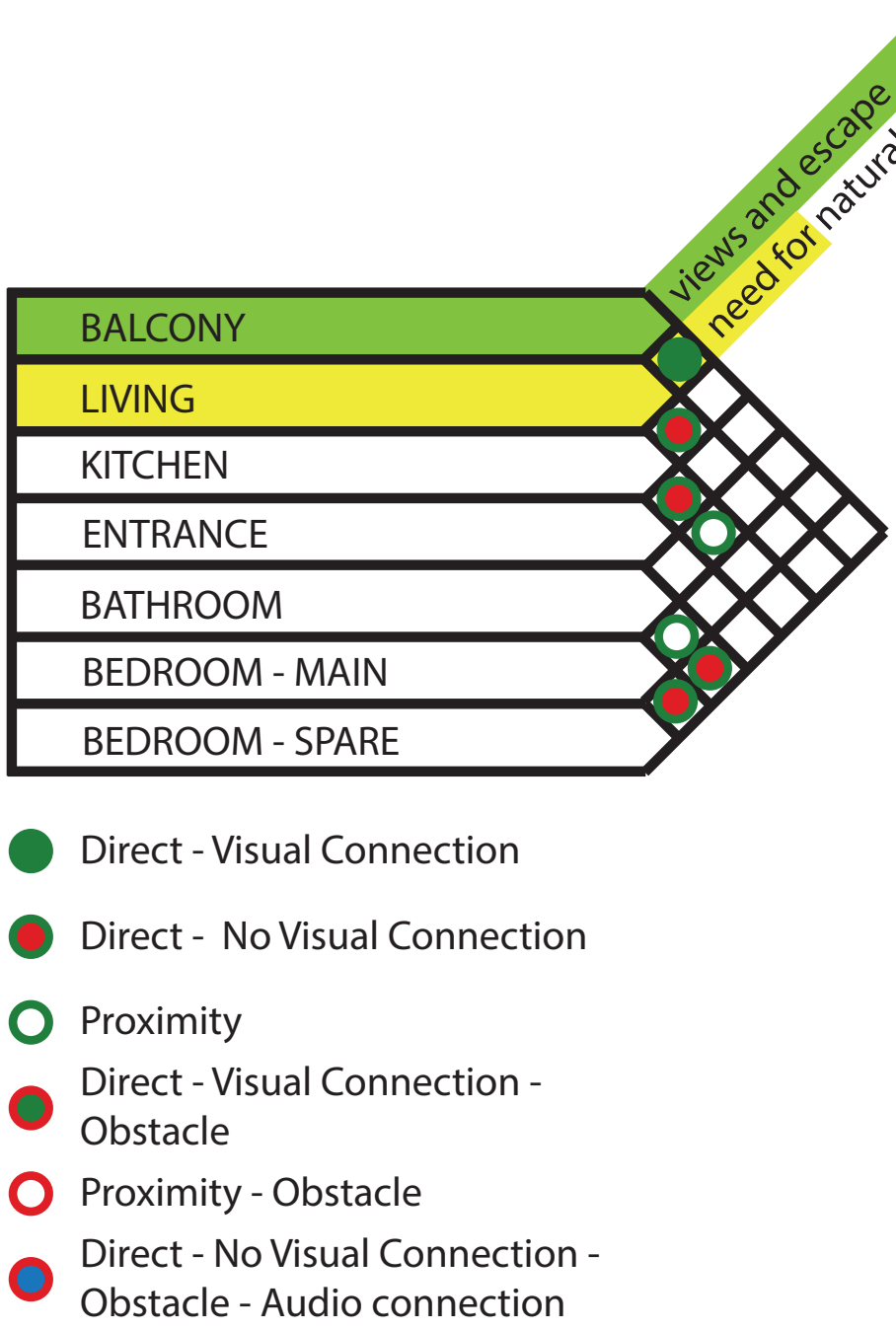




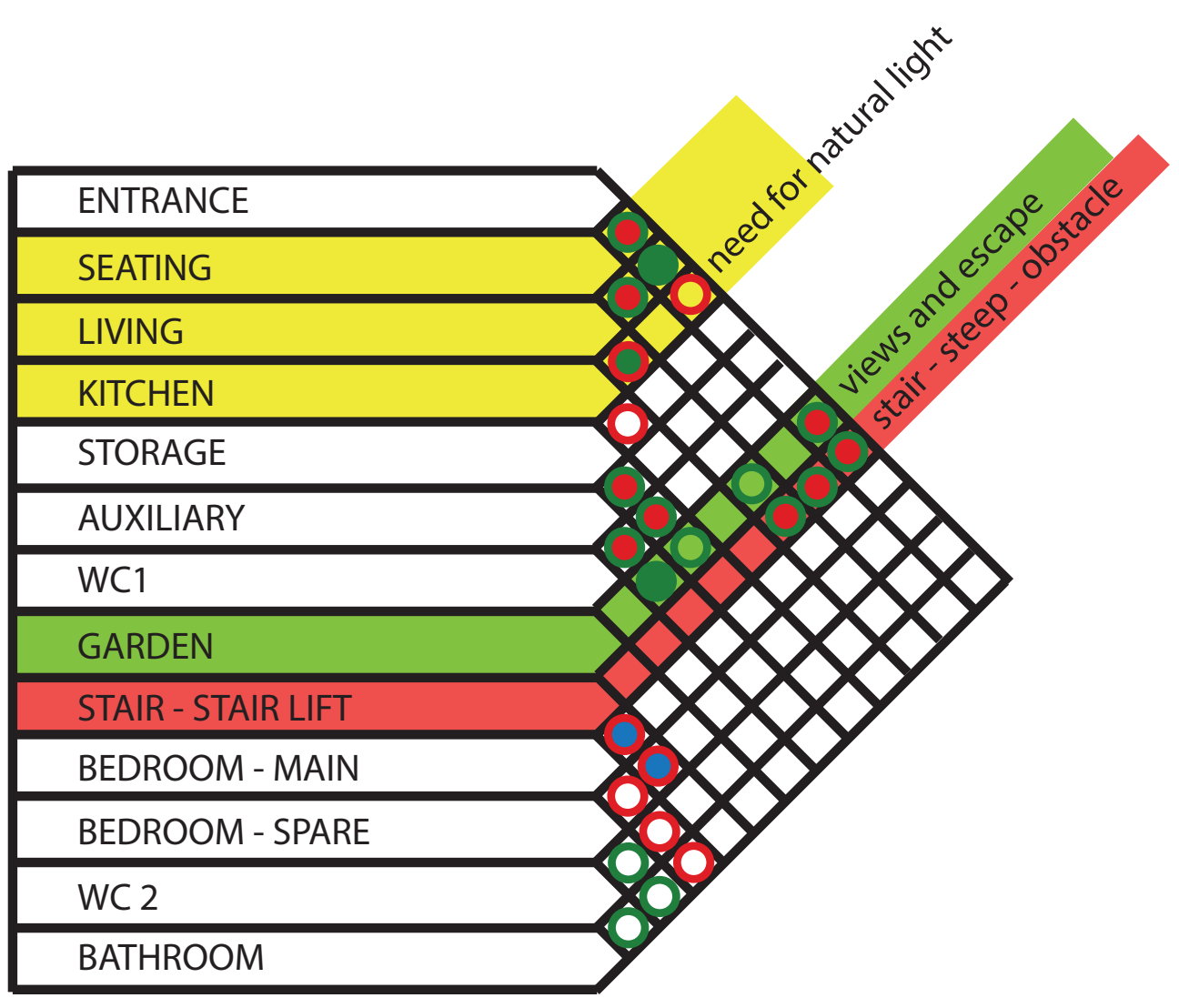

Direct - Visual Connection

Direct - No Visual Connection

Proximity

Direct - Visual Connection -

Obstacle

O Proximity-Obstacle

Direct - No Visual Connection -

Obstacle - Audio connection 